\title{
Phase transition in $\mathrm{NH}_{4} \mathrm{HSO}_{4}$-porous glasses nanocomposites
}

\author{
Agnieszka Ciżman • Tomasz Marciniszyn • \\ Dirk Enke $\cdot$ Andrei Barascu $\cdot$ Ryszard Poprawski
}

Received: 4 March 2013/Accepted: 27 May 2013/Published online: 16 June 2013

(C) The Author(s) 2013. This article is published with open access at Springerlink.com

\begin{abstract}
The results of investigations of porous glasses (PG) and porous glasses-ammonium hydrogen sulfate ferroelectric nanocomposites (AHS-PG) are presented. On the basis of dielectric and calorimetric measurements it was shown that in the AHS-PG nanocomposites with average pore size of 44, 68, 95, and $320 \mathrm{~nm}$ the anomalies of dielectric permittivity and specific heat similar to those in bulk crystals AHS are observed. An influence of the mean value of pores sizes on the ferroelectric phase transition temperatures of AHS nanocrystals embedded into the porous matrices was determined. It was shown that in AHS-PG dispersion of the dielectric permittivity is observed in both para- and ferro-electric phases and above room temperature AHSPG nanocomposites exhibit the ionic conductivity.
\end{abstract}

Keywords Size effect · Ferroelectrics · Porous glasses nanocomposite $\cdot$ AHS nanocompoistes

A. Ciżman · T. Marciniszyn $(\bowtie) \cdot$ R. Poprawski Institute of Physics, Wrocław University of Technology, Wybrzeże Wyspiańskiego 27, 50-370 Wrocław, Poland e-mail: tomasz.marciniszyn@pwr.wroc.pl

D. Enke

Institut für Technische Chemie, Universität Leipzig, Linnéstr. 3, 04103 Leipzig, Germany

\section{A. Barascu}

Institut für Nichtklassische Chemie e.V., Permoserstr. 15, 04318 Leipzig, Germany

\section{Introduction}

The recent theoretical and experimental development of new effects in the nanostructure physics depends greatly on our capability to create successful new types of structures. An understanding of the physical phenomena in ultra-small structures is one of the major issues of the condensed matter physics. Present technology has made it possible to create nanostructures obtained by various methods. In the recent years, a considerable attention was focused on studies of ferroelectric porous glass nanocomposites. The main reason of a porous matrix usage is an ability to produce a controlled pore matrix with a large range of characteristic pore sizes and various geometries of porous matrices. Porous media can be considered as complex systems due to the disorder at the molecular level, the disordered morphology and they are a subject of interest in industrial processes. A usage of porous matrices in manufacturing of ferroelectric nanocomposites has emerged as a new paradigm in high performance materials. A recent research of ferroelectric materials embedded in porous glass matrices showed that the new nanocomposites exhibited different properties than those for bulk and increasingly becoming more attractive for wide variety of applications. An embedding of ferroelectric materials into porous glasses either from the melt or from a water solution is one of recommended methods for obtaining the ferroelectric nanoparticles (Colla et al. 1997; Dorner 
et al. 2003; Ciżman et al. 2012a; Sieradzki et al. 2011).

The ammonium hydrogen sulfate $\mathrm{NH}_{4} \mathrm{HSO}_{4}$ (AHS) belongs to an interesting group of hydrogen bounded materials with a general formula of MHSO4 $(\mathrm{M}=\mathrm{K}$, $\mathrm{Rb}, \mathrm{Cs}, \mathrm{NH}_{4}$ ) (Pepinsky et al. 1958; Cotton et al. 1975; Nelms 1971; Diosa et al. 2001). The phase diagram of AHS crystal is displayed in Fig. 1. At room temperature AHS crystals belong to the monoclinic system with the space group $P 2_{1} / c-C_{2 h}^{5}$ and lattice constants $a=14.51 \AA, b=4.54 \AA$, and $c=14.90 \AA$ (Pepinsky et al. 1958). The AHS crystals exhibit ferroelectric properties in the temperature range from 154 to $270 \mathrm{~K}$ (Pepinsky et al. 1958). At the ferroelectric phase AHS crystals belonging to monoclinic system with space group Pc, the low-temperature phase is triclinic with space group $\mathrm{P} 1$. The high-temperature phase transition (between phase I-II) is second order, while lowtemperature phase transition (II-III) is first order (Pepinsky et al. 1958). The AHS crystal melting point at normal pressure is $420 \mathrm{~K}$. At the high-temperature phase (phase I) AHS crystals exhibit superionic conductivity.

The main goal of this work is to examine the main characteristics of porous glasses and investigation of physical properties and phase transition of AHSporous glass nanocomposites with wide range of mean value of pores dimensions using dielectric spectroscopy and DSC measurements.

\section{Experiment}

Porous glass sample preparation

The composition of the initial glass was $70 \mathrm{SiO}_{2}, 23$ $\mathrm{B}_{2} \mathrm{O}_{3}$, and $7 \mathrm{Na}_{2} \mathrm{O}$ (wt\%). The initial glass was heat treated for $24 \mathrm{~h}$ at 853,833 , and $923 \mathrm{~K}$, respectively to induce the phase separation. The time taken for heat treatment determines the extent of phase separation and the resulting average pore size. Afterward the glass blocks were cooled down rapidly below the critical temperature of phase separation and then slowly cooled within the furnace to room temperature to avoid stresses in the glass. The blocks were then mounted on a ceramic tile and cut into thin slices with an annular saw (Logitech, Annular 50). The thickness of these slices was adjusted to $0.5 \mathrm{~mm}$. The sodium borate phase formed during phase separation was extracted by soaking the samples in hydrochloric acid. After the extraction step the samples were etched in potassium hydroxide solution to remove the secondary silica. This method provides the matrix with average diameter of porous 44,68 , and $95 \mathrm{~nm}$. The method for preparation of pores glasses with mean pore diameter of $320 \mathrm{~nm}$ was described in (Rysiakiewicz-Pasek et al. 2000). The porous glasses were labeled with "PG" symbol followed by their average pore diameter in $\mathrm{nm}$. The preparation conditions for all used porous matrices are summarized in Table 1.

Porous glass matrices characterization

The specific surface areas of the resulting porous glasses were evaluated by low-temperature nitrogen sorption (ASAP 2000, Micromeritics) using the BET equation. For this reason the samples were activated at $393 \mathrm{~K}$ in vacuum for $5 \mathrm{~h}$ to remove physisorbed water. Furthermore, the PGs were characterized by mercury intrusion porosimetry (Thermo Finnigan, Pascal 440).

Table 1 Preparation conditions of the porous glass samples

\begin{tabular}{|c|c|c|c|}
\hline \multirow[t]{2}{*}{ Porous glass (label) } & \multicolumn{2}{|c|}{ Temperature treatment } & \multirow{2}{*}{$\begin{array}{l}\text { Thickness } \\
d(\mathrm{~mm})\end{array}$} \\
\hline & $T(\mathrm{~K})$ & $t(\mathrm{~h})$ & \\
\hline PG44 & 853 & 24 & \multirow{4}{*}{0.5} \\
\hline PG68 & 883 & 24 & \\
\hline PG95 & 923 & 24 & \\
\hline PG320 & 930 & 100 & \\
\hline
\end{tabular}

Fig. 1 Phase diagram of AHS crystal

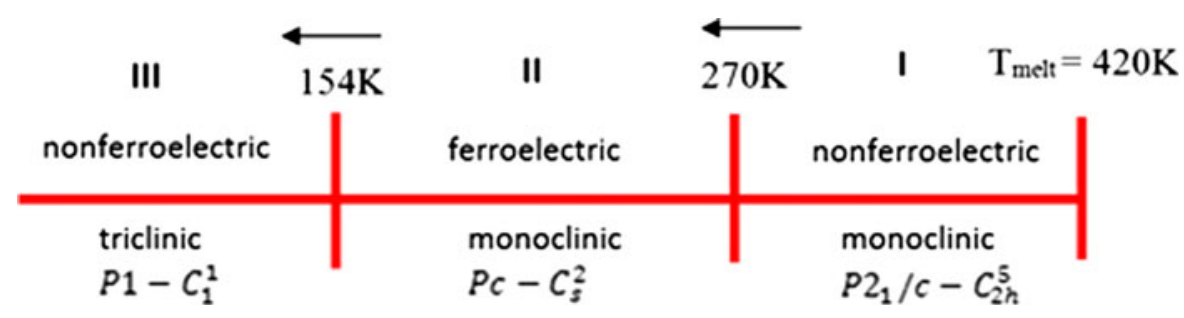


The pore diameter was calculated by applying the Washburn equation and a cylindrical pore model. The pores size distributions of all obtained PG are very narrow as shown in Fig. 2.

The basic parameters of porous glasses and their labels used in the text are shown in the Table 2. It is worth noting that the specific surface area of the pores increases from $6 \mathrm{~m}^{2} / \mathrm{g}$ for PG320 to $48 \mathrm{~m}^{2} / \mathrm{g}$ for PG44.

Scanning Electron Microscopy (SEM) of the porous glass samples was carried out on a Philips ESEM XL 30 FEG microscope. An electron micrograph of the sample with an average pore diameter of $68 \mathrm{~nm}$ is shown in Fig. 3. The micrograph confirms the average pore diameter determined by mercury intrusion, the porosity (about $50 \%$ ), and the more or less cylindrical pore geometry.

Samples preparation and experimental techniques

In order to obtain AHS-PG nanocomposites the porous glass plates of the dimensions $10 \times 10 \times 0.5 \mathrm{~mm}^{3}$ were soaked in ammonium hydrogen sulfate saturated water solution at $365 \mathrm{~K}$ for $2 \mathrm{~h}$. After this process the porous composites were annealed for $1 \mathrm{~h}$ at $400 \mathrm{~K}$ to remove the residual water from the pores. The glasses were placed again in AHS water solution at $365 \mathrm{~K}$. The soaking and annealing processes were repeated three times to promote better pores filling. The filling factor was estimated to be $88 \%$ for all samples. The samples were carefully polished to remove micro-crystals from the surfaces. The samples of AHS crystals embedded into porous matrix were marked as AHS-PG44, AHSPG68, AHS-PG95, and AHS-PG320, respectively.

The dielectric investigations of AHS-PG nanocomposites in the frequency range of $0.1 \mathrm{~Hz}-1 \mathrm{MHz}$ and the temperature range of 120-300 K were carried out with aid of a High Performance Dielectric Spectrometer (Novocontrol) with the automatic temperature control.

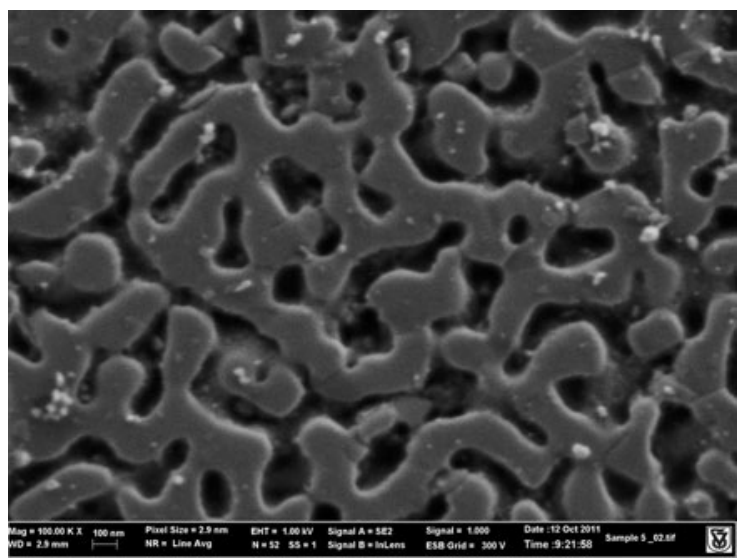

Fig. 3 Electron micrograph of the porous glass plate with $68 \mathrm{~nm}$ pore diameter
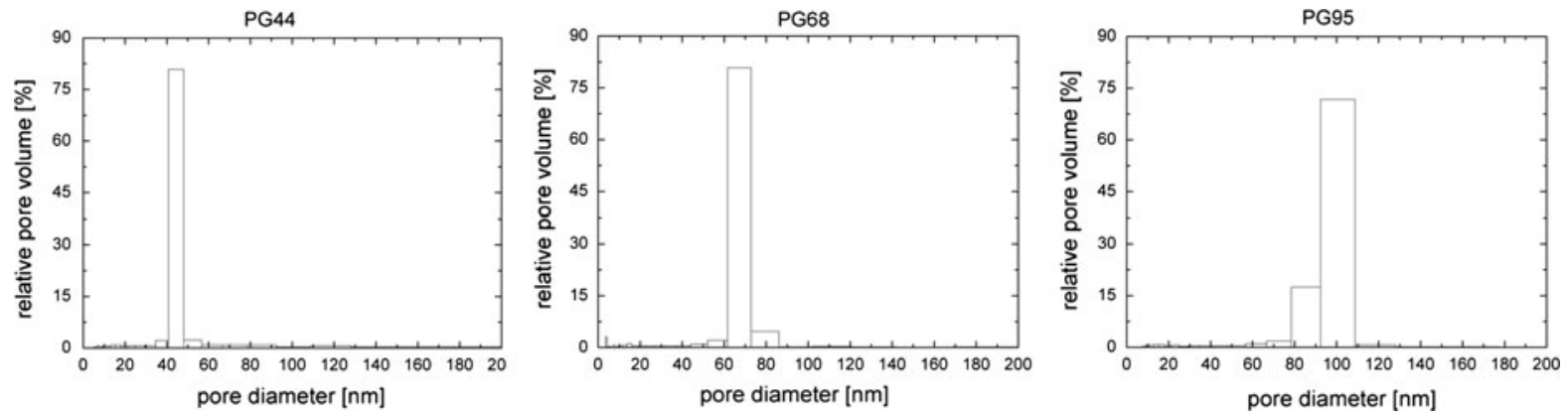

Fig. 2 Pore size distributions for PG44, PG68, and PG95 determined by mercury intrusion porosimetry

Table 2 Textural properties of the porous glass samples

${ }^{\text {a }}$ Calculated from mercury intrusion data

b Calculated from low temperature nitrogen sorption data

\begin{tabular}{lllll}
\hline Porous glass & $\begin{array}{l}\text { Cumulative pore } \\
\text { volume } \\
V_{\mathrm{p}}\left(\mathrm{cm}^{3} / \mathrm{g}\right)\end{array}$ & $\begin{array}{l}\text { Average pore } \\
\text { diameter } \\
d_{\mathrm{P}}(\mathrm{nm})\end{array}$ & $\begin{array}{l}\text { Porosity } \\
\varepsilon(\%)\end{array}$ & $\begin{array}{l}\text { Specific surface } \\
\text { area }(\mathrm{BET}) \\
A_{\text {S-BET }}\left(\mathrm{m}^{2} / \mathrm{g}\right)\end{array}$ \\
\hline PG44 & $0.42^{\mathrm{b}}$ & $44^{\mathrm{a}}$ & 48 & $32^{\mathrm{b}}$ \\
PG68 & $0.48^{\mathrm{a}}$ & $68^{\mathrm{a}}$ & 52 & $24^{\mathrm{b}}$ \\
PG96 & $0.47^{\mathrm{a}}$ & $95^{\mathrm{a}}$ & 51 & $18^{\mathrm{b}}$ \\
PG320 & $0.47^{\mathrm{a}}$ & $320^{\mathrm{a}}$ & 51 & $5.9^{\mathrm{a}}$ \\
\hline
\end{tabular}



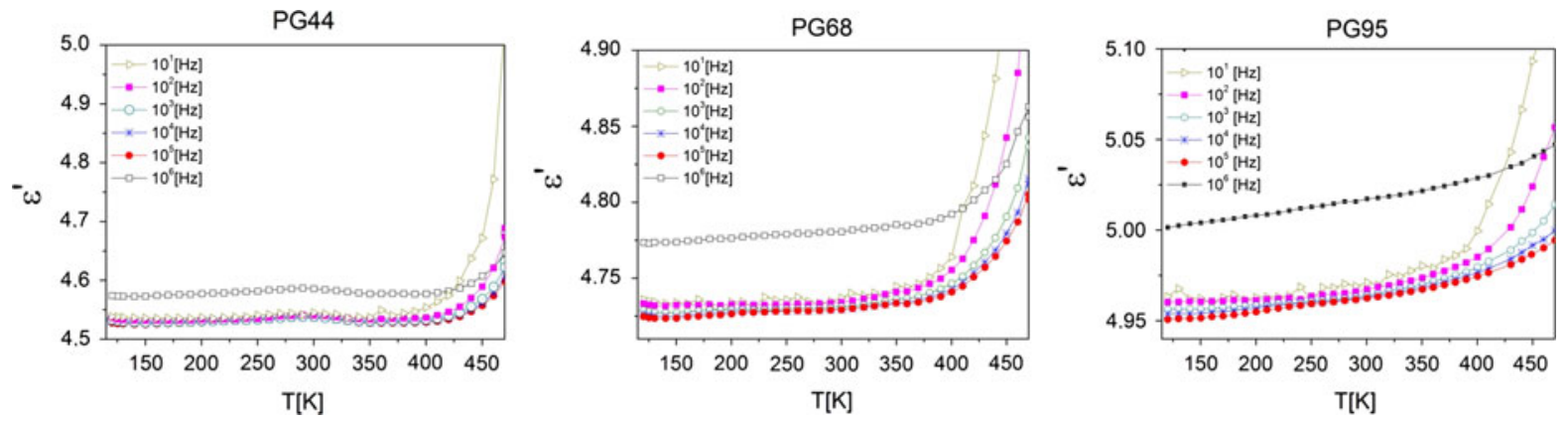

Fig. 4 Temperature dependences of the dielectric permittivity of PG44, PG68, and PG95 empty porous matrices for several frequencies

The dielectric response was studied on a plane-parallel plate with silver paint paste electrodes.

The measurements of the electric permittivity and the loss tangent were performed with an accuracy of $3 \%$. The experiments were performed in $1 \mathrm{~K}$ temperature steps.

The specific heat measurements were performed using differential scanning calorimeter DSC-1 Mettler Toledo equipped with 120 thermocouples sensor HSS8. The resolution of measured signal was $0.01 \mu \mathrm{W}$. During measurements the samples were exposed to a dry nitrogen atmosphere. Calorimetric measurements were carried out on heating and cooling rate in temperature range from $130 \mathrm{~K}$ to about $280 \mathrm{~K}$ with the scanning rate $2 \mathrm{~K} / \mathrm{min}$. Before each measurement, the residual water absorbed in the pores was removed by annealing the samples at $380 \mathrm{~K}$ for $1 \mathrm{~h}$.

\section{Results and discussions}

Dielectric properties of porous matrices

In Fig. 4 the temperature dependences of the real part of the dielectric permittivity for porous matrices PG44, PG68, and PG95 are presented for several frequencies. We readily see that in the temperature range from 120 to $400 \mathrm{~K}$ dielectric permittivity practically does not depend on temperature and very weakly depends on the frequency (for frequencies $<10^{5} \mathrm{~Hz}$ ). For frequency values $>10^{5} \mathrm{~Hz}$ the permittivity increases with increasing frequency. We can thus maintain that observed effect is probably associated with the piezoelectric resonance in the quartz microcrystal's forming the porous matrix.
Dielectric and thermal properties and phase transition in $\mathrm{NH}_{4} \mathrm{HSO}_{4}-\mathrm{PG}$ nanocomposites

The temperature dependence of the real part of the electric permittivity for several frequencies obtained on cooling process for AHS-PG nanocomposites with different pore diameter is presented in Fig. 5. For all AHS-PG nanocomposites the ferroelectric phase transitions are indicated by well-defined anomalies of the temperature dependences of dielectric permittivity. A dispersion of the dielectric permittivity is observed in both para- and ferro-electric phases. The anomaly of dielectric permittivity in the II-III phase transition region remains typical for smeared firstorder phase transition, while the area around I-II phase transition is characteristic for smeared second-order phase transition.

The analysis of the dielectric measurement results for AHS-PG nanocomposites was performed to create the phase diagram. It represents the relationship between the phase transition temperatures $T p$ and particle size.

The phase transition temperatures TpII-III were determined as a peak of derivatives of $\varepsilon^{\prime}(T)$ for the II-III phase transition, while TpI-II were determined as the maximum of the electric permittivity at a frequency of $1 \mathrm{MHz}$.

The phase transition temperature-size phase diagrams for low and high-temperature phase transitions of AHS-PG nanocomposites are presented in Fig. $6 a, b$ respectively. One can notice the nonmonotonic dependence of the phase transition temperature $T \mathrm{pII}-\mathrm{III}$ on the mean value of pores size. This experimental observation is characteristic for ferroelectrics with negative extrapolation length. We would 

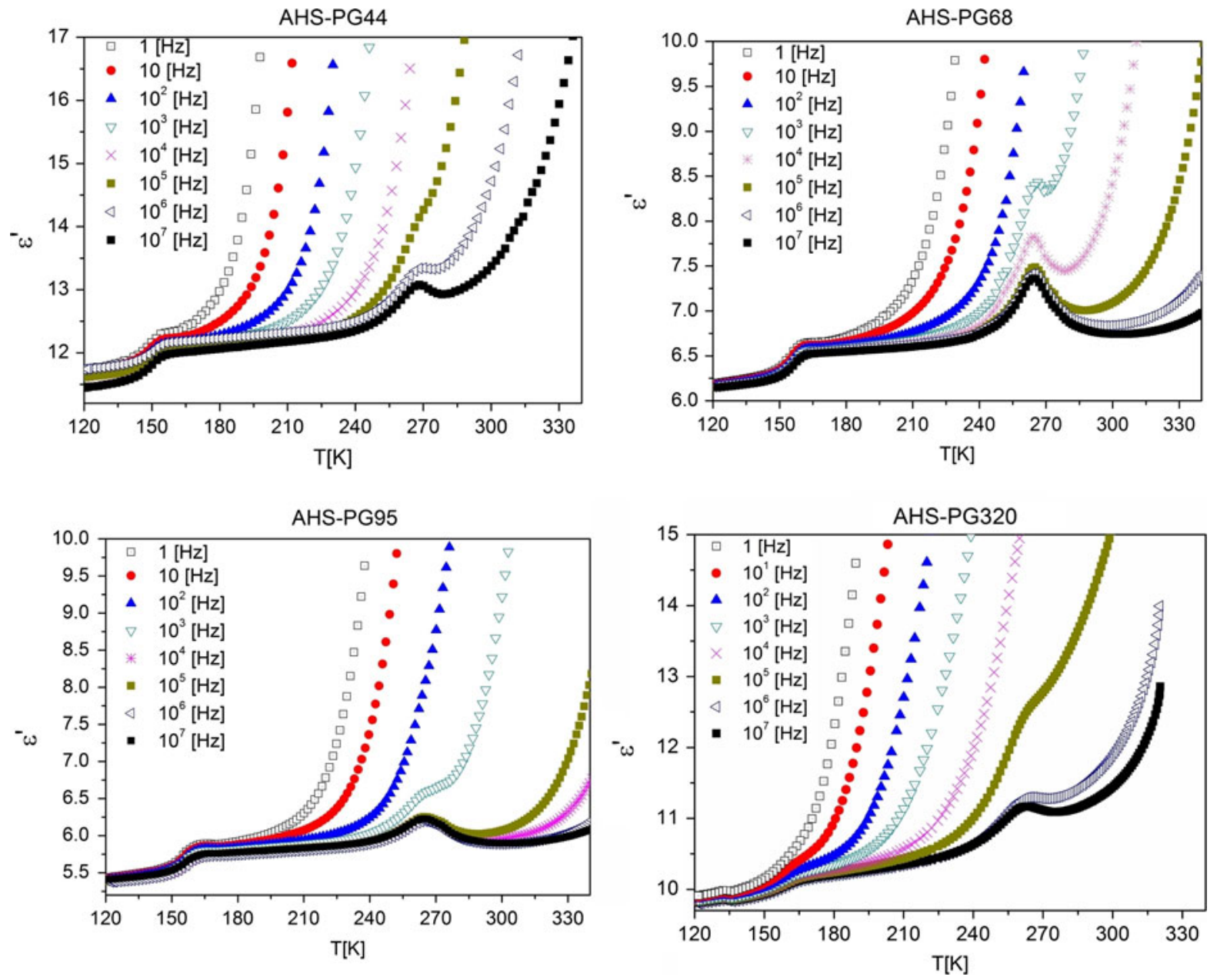

Fig. 5 Temperature dependence of the real part of the dielectric permittivity for selected frequencies for AHS-PG nanocomposites
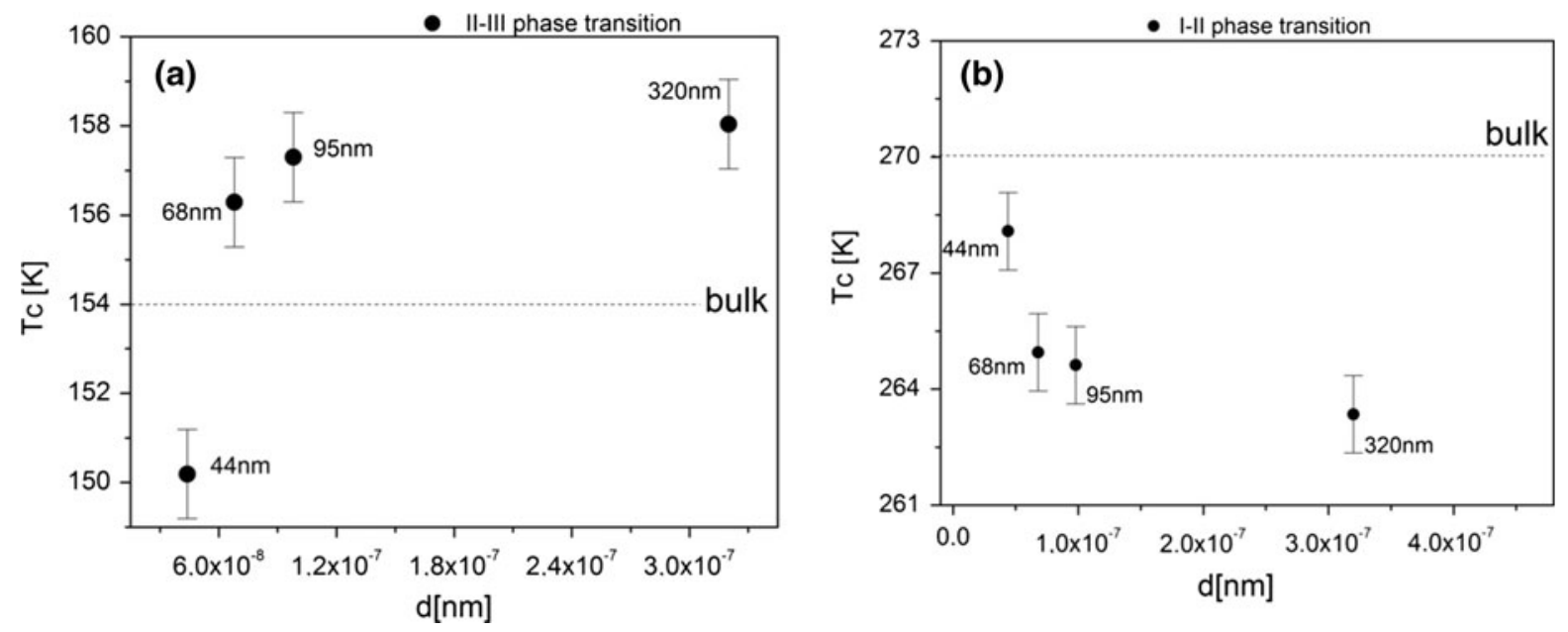

Fig. 6 Phase transitions temperatures of AHS-PG nanocomposites as a function of the mean value of pores diameter determined from the results of dielectric measurements presented on Fig. 5 
like to emphasize that the similar behavior was observed for KDP-PG nanocomposites (Ciżman et al. 2012b).

The size dependence of the low-temperature phase transition temperature can be explained based on the phenomenological model (Zhong et al. 1994; Charnaya et al. 2007). According to (Zhong et al. 1994), the phase transition temperature of the spherical particles with diameter $\mathrm{d}$ belonging to the cubic system can be described by equation:

$T_{C}=T_{c . \infty}-\frac{6 D}{\delta_{\infty} A d}$

where $T_{C \infty}$ is the Curie-Weiss temperature of bulk crystals, $D$ is connected with correlation length, $A$ is the Landau expansion coefficient, and $\delta_{\infty}$ is the extrapolation length. The extrapolation length describes the polarization gradient at the surface of the crystals. If the polarization at the surface (Psurf) is greater than the crystal interior polarization (Pint), then $\delta_{\infty}<0$ otherwise when Psurf $<$ Pint then $\delta_{\infty}>0$ (Zhong et al. 1994). For $\delta_{\infty}>0$ the particle size reduction causes the phase transition temperature decrease as compared to the bulk crystals, whereas for $\delta_{\infty}<0$ the reduction of the particle size causes initially a rise of the phase transition temperature and then its drop.

The temperature dependences of the specific heat $\mathrm{Cp}$ during the cooling and heating rate of the AHSPG68 nanocomposites are presented in Fig. 7. The entropy change $\Delta S$ associated with the phase transitions at AHS embedded into PG68 is presented in Fig. 8. The anomaly of the specific heat and entropy changes as well as wide thermal hysteresis (13 K) of thermal properties which accompanies the first-order phase transition at low-temperature phase transition can be clearly seen. The anomaly of the specific heat and continuous entropy changes in the region of hightemperature phase transition and lack of an explicit of thermal hysteresis confirm the existence of the secondorder phase transition in discussed high-temperature region. The entropy jump at the low-temperature phase transition (II-III) in AHS-PG 68 is about $2.56 \mathrm{~J} / \mathrm{mol} \mathrm{K}$ and is much smaller than that determined for bulk crystals (6.7 J/mol K (Pepinsky et al. 1958)). This fact indicates that the surface layer does not contribute to a phase transition. Similar conclusions can be drawn from the temperature dependence of entropy in the vicinity of the upper (I-II) phase transition.

We can draw the conclusion from the results of dielectric and calorimetric investigation of AHS-PG

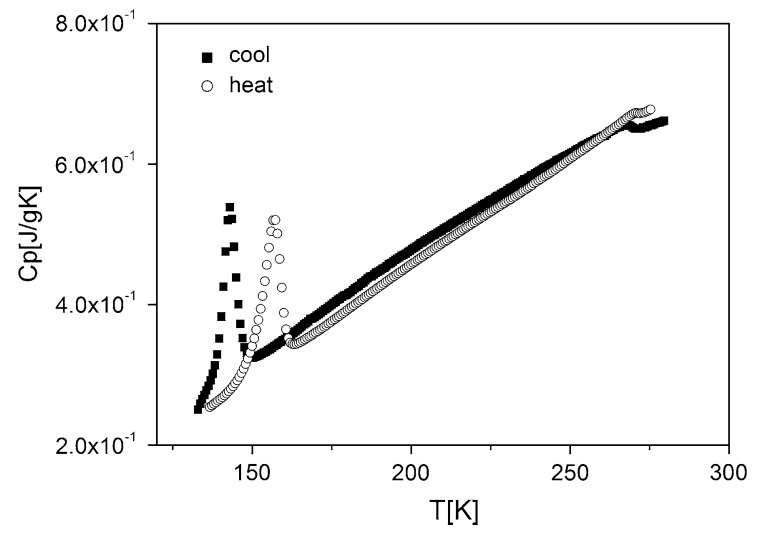

Fig. 7 Temperature dependences of specific heat for the AHSPG68 nanocomposite

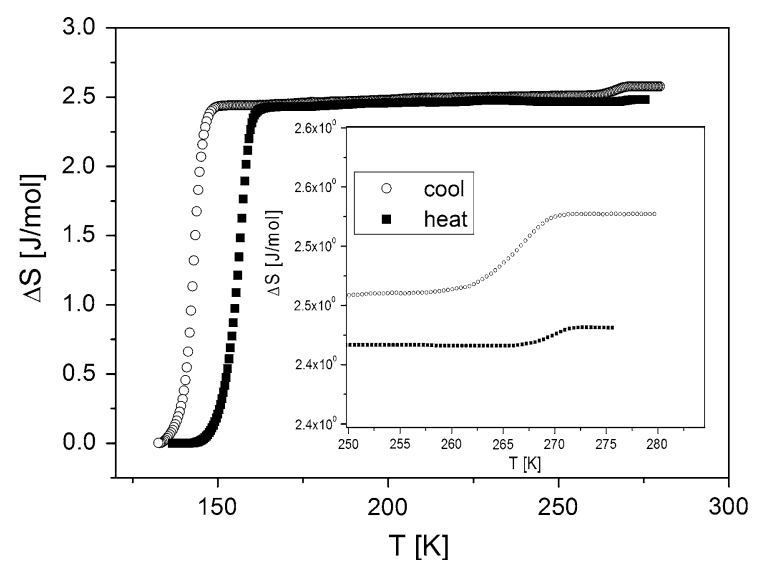

Fig. 8 Temperature dependences of anomalous part of entropy changes for AHS formed inside the porous glass PG68

nanocomposites that the particle size reduction does not affect the phase transition order. This remark is in agreement with the conclusion driven from the phenomenological model (Zhong et al. 1994; Charnaya et al. 2007).

\section{Electrical conductivity of AHS-PG nanocomposites}

The low-frequency electrical conductivity of AHSPG nanocomposites were determined between 348 and $400 \mathrm{~K}$ on the basis of low-frequency electric permittivity measurements. Temperature dependence of the electrical conductivity for AHS-PG68 nanocomposites in the high-temperature range for $1 \mathrm{~Hz}$ is illustrated in Fig. 9. 


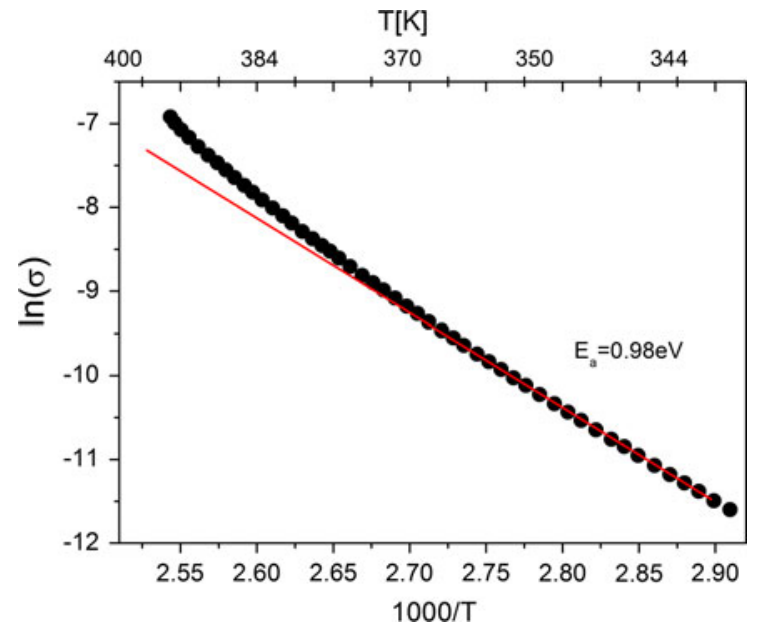

Fig. 9 The $\ln \sigma$ dependence of the inverse temperature for AHS-PG68 nanocomposite

An Arrhenius-type activation process with an activation energy $E_{\mathrm{a}}$ of $0.98-1.2 \mathrm{eV}$ is observed in the temperature range between 330 and $390 \mathrm{~K}$. The activation energy of the conductivity process in AHSPG nanocomposites is larger than that obtained for the DC conductivity of bulk AHS crystals $(0.58-0.8 \mathrm{eV})$ (Reddy et al. 1982).

\section{Conclusions}

The AHS nanocomposites embedded into porous matrices with a mean value of pore diameter of 44,68 , 95, and $320 \mathrm{~nm}$ were investigated. In all nanocomposites anomalies of dielectric permittivity and specific heat characteristic of ferroelectric phase transitions in bulk AHS crystals were observed. The result of dielectric study clearly shows that the shift of phase transitions temperatures of AHS nanocrystals formed inside the porous matrices depends on pore diameter. The shift of the low temperature phase transition can be explained by the theoretical considerations for ferroelectrics by which the polarization of the surface layer is greater or lower than the polarization in the volume of the crystallites (Zhong et al. 1994). Based on dielectric and calorimetric studies it was shown that the size effect does not change the order of the phase transitions. In addition, it could be shown that in AHS-PG a lowfrequency dispersion of the dielectric permittivity is observed in both para- and ferro-electric phases. Above room temperature the AHS-PG nanocomposites exhibit high ionic conductivity.

Acknowledgments We gratefully acknowledge the efforts of Dr E. Rysiakiewicz- Pasek for the porous matrix PG320nm.

Open Access This article is distributed under the terms of the Creative Commons Attribution License which permits any use, distribution, and reproduction in any medium, provided the original author(s) and the source are credited.

\section{References}

Charnaya V, Pirozerskii AL, Tien C, Lee MK (2007) Ferroelectricity in an array of electrically coupled confined small particles. Ferroelectrics 350:75-80

Ciżman A, Marciniszyn T, Poprawski R (2012a) Pressure effect on the ferroelectric phase transition in nanosized $\mathrm{NH}_{4} \mathrm{HSO}_{4}$. J Appl Phys 112:034104-034106

Ciżman A, Marciniszyn T, Rysiakiewicz-Pasek E, Sieradzki A, Antropova TV, Poprawski R (2012b) Phase transition in $\mathrm{NH}_{4} \mathrm{H}_{2} \mathrm{PO}_{4}$ : porous glass composites. Phase Tran. doi: 10.1080/01411594.2012.745537

Colla EV, Fokin AV, Kumzerov Yu A (1997) Ferroelectrics properties of nanosize KDP particles. Solid State Comm 103(2):127-130

Cotton FA, Frenz BA, Hunter DL (1975) The structure of potassium hydrogen sulfate. Acta Crystallogr B 31: 302-304

Diosa JE, Fernández ME, Vargas RA (2001) Anomalous phase behaviour of $\mathrm{NH}_{4} \mathrm{HSO}_{4}$ below room temperature. Phys Stat Sol (b) 227:458-465

Dorner B, Golosovsky I, Kumzerov Yu, Kurdyukov D, Naberezhnov A, Sotnikov A, Vakhrushev S (2003) Structure of $\mathrm{KD}_{2} \mathrm{PO}_{4}$ embedded in a porous glass. Ferroelectrics 286 : 213-219

Nelms RJ (1971) An X-ray diffraction determination of the crystal structure of ammonium hydrogen sulphate above the ferroelectric transition. Acta Crystallogr B 27:272-281

Pepinsky R, Vedam K, Okaya YS, Hoshino S (1958) Ammonium hydrogen sulfate: a new ferroelectric with low COERCIVE field. Phys Rev 111(6):1508-1510

Reddy AD, Sathyanarayan SG, Sastry GS (1982) Proton conduction in $\left(\mathrm{NH}_{4}\right) \mathrm{HSO}_{4}$ single crystals. Phys Stat Sol (a) $73: \mathrm{K} 41-\mathrm{K} 45$

Rysiakiewicz-Pasek E, Lukaszewicz P, Bogdanska J (2000) Influence of water adsorption on mechanical properties of porous glasses. Optica Applicata 30:173-176

Sieradzki A, Cizman A, Poprawski R, Marciniszyn T, Rysiakiewicz-Pasek E (2011) Electrical conductivity and phase transitions in KDO- and ADP porous glass nanocomposites. J Adv Dielectr 1(3):337-343

Zhong WL, Wang YG, Zhang PL, Qu BD (1994) Phenomenological study of the size effect on phase transitions in ferroelectric particles. Phys Rev B 50:698-703 